\title{
Thermally driven molecular linear motors - A molecular dynamics study
}

\author{
Zambrano, Harvey A; Walther, Jens Honore; Jaffe, Richard Lawrence
}

Published in:

Journal of Chemical Physics

Link to article, DOI:

$10.1063 / 1.3281642$

Publication date:

2009

Document Version

Publisher's PDF, also known as Version of record

Link back to DTU Orbit

Citation (APA):

Zambrano, H. A., Walther, J. H., \& Jaffe, R. L. (2009). Thermally driven molecular linear motors - A molecular dynamics study. Journal of Chemical Physics, 131(24), 241104. https://doi.org/10.1063/1.3281642

\section{General rights}

Copyright and moral rights for the publications made accessible in the public portal are retained by the authors and/or other copyright owners and it is a condition of accessing publications that users recognise and abide by the legal requirements associated with these rights.

- Users may download and print one copy of any publication from the public portal for the purpose of private study or research.

- You may not further distribute the material or use it for any profit-making activity or commercial gain

- You may freely distribute the URL identifying the publication in the public portal

If you believe that this document breaches copyright please contact us providing details, and we will remove access to the work immediately and investigate your claim. 


\title{
Thermally driven molecular linear motors: A molecular dynamics study
}

\author{
H. A. Zambrano, ${ }^{1}$ J. H. Walther, ${ }^{1, a)}$ and R. L. Jaffe ${ }^{2}$ \\ ${ }^{1}$ Department of Mechanical Engineering, Technical University of Denmark, DK-2800 Lyngby, Denmark \\ ${ }^{2}$ NASA Ames Research Center, Moffett Field, California 94035, USA
}

(Received 18 September 2009; accepted 8 December 2009; published online 29 December 2009)

\begin{abstract}
We conduct molecular dynamics simulations of a molecular linear motor consisting of coaxial carbon nanotubes with a long outer carbon nanotube confining and guiding the motion of an inner short, capsulelike nanotube. The simulations indicate that the motion of the capsule can be controlled by thermophoretic forces induced by thermal gradients. The simulations find large terminal velocities of $100-400 \mathrm{~nm} / \mathrm{ns}$ for imposed thermal gradients in the range of $1-3 \mathrm{~K} / \mathrm{nm}$. Moreover, the results indicate that the thermophoretic force is velocity dependent and its magnitude decreases for increasing velocity. (C) 2009 American Institute of Physics. [doi:10.1063/1.3281642]
\end{abstract}

In recent experimental studies, Somada et al. ${ }^{1}$ and Barreiro et al. ${ }^{2}$ fabricated molecular linear motors consisting of coaxial carbon nanotubes (CNTs). In both systems a short $\mathrm{CNT}$ is found to move along the axis of a long CNT, working as a molecular linear motor. Barreiro et al. ${ }^{2}$ were able to attach a cargo to an ablated outer wall of a multiwalled CNT and to impart translational and rotational motion of the cargo by imposing a thermal gradient. Barreiro et $a l^{2}{ }^{2}$ identified thermophoresis as the main driving mechanism for their motor and consistent with recent numerical simulations of thermophoretic motion of gold nanoparticles and water nanodroplets confined inside CNTs. ${ }^{3-6}$ In the experimental arrangement of Somada et al. ${ }^{1}$ the system was described and modeled as a capped capsule-like short CNT with a chiral vector of $(12,0)$ encapsulated in the interior hollow space of a single wall CNT with a chiral vector of $(22,0)$. The hollow space was approximately $8.5 \mathrm{~nm}$ long and limited by two fixed and inner CNTs with a chiral vector of $(12,0)$. The total length of the outer CNT was more than $100 \mathrm{~nm}$ long. Using transmission electron microscopy (TEM), Somada et al. ${ }^{1}$ observed that the inner CNT (capsule) changed its position including stop events at the two ends of the hollow space. During the $170 \mathrm{~s}$ long experiment, the capsule was found to travel back and forth seven times. However the motion of the capsule could only be observed indirectly due to $0.5 \mathrm{~s}$ time resolution of the TEM. The pictures obtained from the TEM experiment furthermore indicate that the capsule is undergoing rotation during the translational motion. Somada et al. ${ }^{1}$ proposed that the mechanism driving the capsule is related to thermal activation energy which is in equilibrium with the van der Waals (vdW) energy gain due to the interaction between the caps of the inner CNTs. ${ }^{7}$ However, the theoretical activation time is shorter than the activation time measured in the experiments, and Somada and co-workers ${ }^{1}$ included an additional contribution to the total friction force due to the thermal fluctuation of the outer CNT. They argue that the thermal energy not only activated the capsule motion but

\footnotetext{
a) Also at Computational Science and Engineering Laboratory, ETH Zürich, Universitätsstrasse 6, CH-8092 Zürich, Switzerland. Electronic mail: jhw@mek.dtu.dk.
}

also obstructed its travel by deforming the hollow space of the system. In a related study, Smith et $a l^{8}{ }^{8}$ found that fullerenes encapsulated inside CNTs would jumped nanometer distances under TEM illumination. The authors ascribed this motion to thermal or electrostatic forces. In order to employ the concept of a molecular linear nanomotor with potential applications such as mass nanotransport systems ${ }^{9-13}$ and archival memory devices, ${ }^{14}$ a detailed explanation of the driving mechanisms should be addressed. In the present Communication we study the ability of thermal gradients and the associated thermophoretic forces to impart motion in CNT-based linear motors. The thermal gradient may be imposed by irradiation from a transmission electron microscope or from Joule heating induced by electrical currents. In experimental and theoretical studies Howe et al. ${ }^{15}$ Yokota et al., ${ }^{16}$ Wang et al.,${ }^{17}$ and Biskupek et al. ${ }^{18}$ found that electron beam irradiation generates a temperature increase in the irradiated region due to electron thermal spikes. Moreover, induced effects such as defect production, annealing and heating by electron-phonon coupling have been investigated by Krasheninnikov. ${ }^{19,20}$ Using molecular dynamics (MD) simulations, Krasheninnikov ${ }^{19}$ argued that, in carbon nanostructures, the kinetic energy of an incident electron beam is converted into thermal energy, which results in an increase in temperature that is higher than expected for bulk systems due to the small system size.

In this work we perform MD simulations in order to demonstrate that the motion of the inner CNT, in a system similar to that studied by Somada et al., ${ }^{1}$ may be strongly influenced by thermophoretic forces. We show quantitatively that a thermal gradient as small as $1.2 \mathrm{~K} / \mathrm{nm}$ can cause the motion of the capsule. For our simulations we use the MD package FASTTUBE, ${ }^{21}$ which has been used extensively to study thermophoretic motion of liquids and solids confined inside single and double wall CNTs. ${ }^{3-6,13}$ We simulate the system studied by Somada et al. ${ }^{1}$ using a double wall CNT system as illustrated in Fig. 1. The system consists of an outer $42.6 \mathrm{~nm}$ long CNT with a chiral vector of $(22,0)$ corresponding to a diameter of $1.723 \mathrm{~nm}$. The inner capsule is modeled as an open short $3.195 \mathrm{~nm}$ long CNT with a chiral vector of $(12,0)$, and diameter $0.94 \mathrm{~nm}$. We describe the va- 


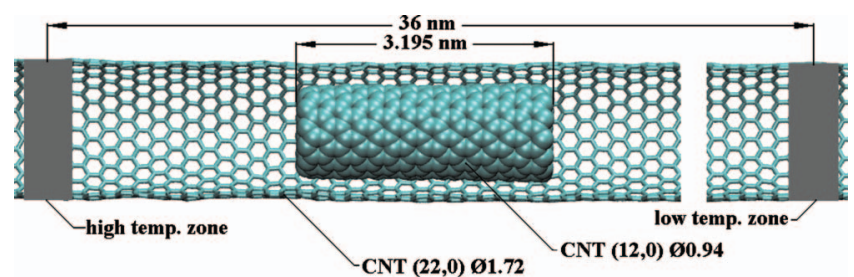

FIG. 1. Schematic of the computational setup. Cross-sectional view of the system, the outer CNT is a $(22,0)$ zigzag CNT and the inner one is a $(12,0)$ zigzag CNT. A thermal gradient is imposed by heating the end sections (in gray) of the outer CNT.

lence forces within the CNT using Morse, harmonic angle and torsion potentials. ${ }^{21} \mathrm{We}$ include a nonbonded carboncarbon Lennard-Jones potential with parameters $\epsilon_{\mathrm{CC}}$ $=0.4396 \mathrm{~kJ} / \mathrm{mol}$ and $\sigma_{\mathrm{CC}}=0.3851 \mathrm{~nm}$ to describe the $\mathrm{vdW}$ interaction between the carbon atoms within the double wall portion of the system. We equilibrate the system at $300 \mathrm{~K}$ for $0.1 \mathrm{~ns}$, by coupling the system to a Berendsen thermostat with a time constant of $0.1 \mathrm{ps}$. After the equilibration we impose thermal gradients in the range of $0.00-4.20 \mathrm{~K} / \mathrm{nm}$ by heating two zones at the ends of the outer CNT as illustrated in Fig. 1. We measure the position of the center of mass (COM) of the inner CNT during the simulation. We observe, for gradients higher that $1.18 \mathrm{~K} / \mathrm{nm}$, a directed motion of the capsule in the direction opposite to the imposed thermal gradient, as shown in Fig. 2(a). For a thermal gradient of 1.18 $\mathrm{K} / \mathrm{nm}$ the mean terminal velocity is approximately $170 \mathrm{~nm} /$ $\mathrm{ns}$, which is higher than the velocity measured in our previ-
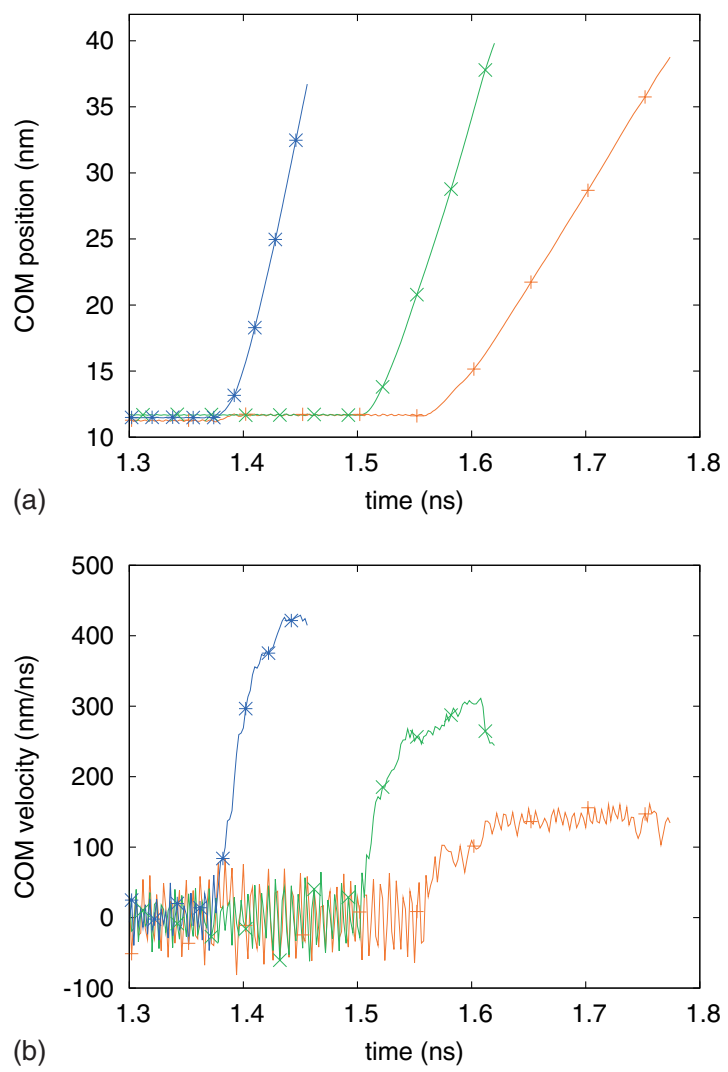

FIG. 2. COM position (a) and velocity (b) as a function of time for three different thermal gradients: blue $(*), 3.16 \mathrm{~K} / \mathrm{nm}$; green $(\times), 1.58 \mathrm{~K} / \mathrm{nm}$, and red $(+), 1.18 \mathrm{~K} / \mathrm{nm}$
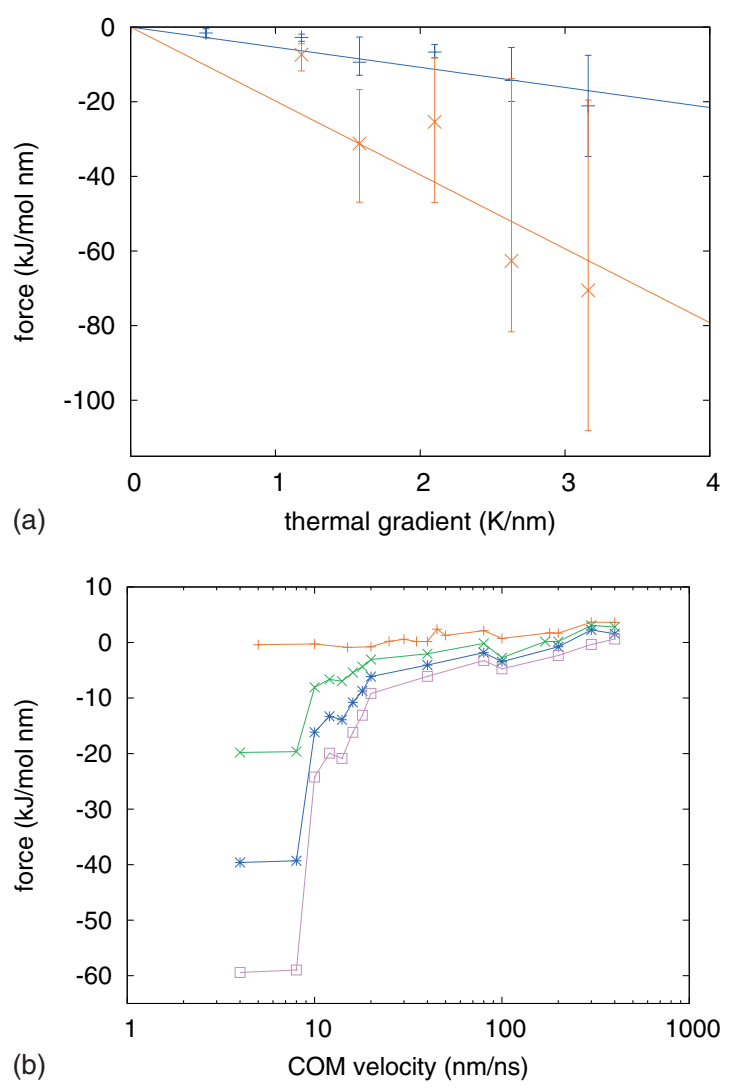

FIG. 3. External force acting on the constrained inner CNT (a) external force as a function of the imposed thermal gradient for different constrained velocities: red line and $(\times), 4 \mathrm{~nm} / \mathrm{ns}$. blue line and $(+), 16 \mathrm{~nm} / \mathrm{ns}$. (b) External force acting as a function of the COM velocity for different thermal gradients: red $(+), 0.0 \mathrm{~K} / \mathrm{nm}$; green $(\times), 1.0 \mathrm{~K} / \mathrm{nm}$; blue $(*), 2.0 \mathrm{~K} / \mathrm{nm}$; and fuchsia (squares), $3.0 \mathrm{~K} / \mathrm{nm}$.

ous studies on thermophoresis of water nanodroplets and gold nanoparticles confined inside $\mathrm{CNTs}^{3-6}$ but similar to the velocity measured in the simulations by Barreiro et al. ${ }^{2}$ Moreover, we find a consistent increase in the terminal velocity for increasing thermal gradients [see Fig. 2(b)]. We observe from the time history of the COM position and velocity (Fig. 2) an initial oscillation of the capsule due to the static friction acting between the two CNTs.

To confirm that the motion of the capsule is driven by thermophoresis we perform additional simulations in order to study the friction and thermophoretic forces acting on the inner CNT. We carry out a force analysis similar to that performed by Schoen et al. ${ }^{3}$ In these simulations, we constrain the COM velocity of the inner CNT and extract from the simulations the external forces required to drive the inner CNT for different constrained velocities and different imposed thermal gradients (Fig. 3). To measure the isothermal friction of the system we impose a zero thermal gradient while we vary the constrained COM velocity. At nonzero thermal gradients we measure the combined friction and thermophoretic forces. A positive force indicates resistance to the motion, whereas a negative force is indicative of thermophoresis. In Fig. 3(a) we show the mean external force as a function of the imposed thermal gradient for two constrained COM velocities. The external forces are subject to large fluctuations represented by the error bars in the corre- 
sponding curve. In Fig. 3(b) we show the external driving forces as a function of the COM velocity for different thermal gradients $(0.0,1.0,2.0$, and $3.0 \mathrm{~K} / \mathrm{nm})$, extracted from more than eighty individual simulations. We find a systematic increase in the thermophoretic force as higher thermal gradients are imposed on the system. Furthermore, the measured isothermal friction is small compared with the thermophoretic force (cf. Fig. 3). We infer from the simulations that the magnitude of the thermophoretic force is reduced as a higher velocity is imposed to the inner CNT (Fig. 3). We conjecture that the magnitude of the driving thermophoretic force is inversely dependent on velocity, We find that, for different imposed thermal gradients, the corresponding terminal velocity is governed by the velocity dependence of the thermophoretic force rather than a match between the thermophoretic force measured at zero velocity and the static friction. We observe from Fig. 3(b) that the zero external force is obtained at approximately $100 \mathrm{~nm} / \mathrm{ns}$ for $1 \mathrm{~K} / \mathrm{nm}$, at $250 \mathrm{~nm} / \mathrm{ns}$ for $2 \mathrm{~K} / \mathrm{nm}$ and at $400 \mathrm{~nm} / \mathrm{ns}$ for $3 \mathrm{~K} / \mathrm{nm}$ in reasonable agreement with the terminal velocities observed in Fig. 2(b).

In summary, we propose that the motion of the molecular linear motor observed in the experiments of Somada et $a l .{ }^{1}$ and Barreiro et $a l .^{2}$ could be caused by the thermal gradient imposed on the system. We believe that the thermal activation energy as proposed by Somada et al. ${ }^{1}$ for the driven mechanism, could be part of the mechanism to extricate the capsule from the energy valley at the ends of the hollow space. However, we believe that this motion may be strongly influenced by thermophoretic forces. We believe that our hypothesis contributes to the understanding and utilization of thermophoresis-based linear nanomotors with potential applications in transport and delivery of substances encapsulated in carbon nanostructures confined inside a host $\mathrm{CNT}^{22-28}$ Moreover, with this Communication we hope to encourage more experimental work to study thermophoretic linear nanomotors and its potential applications.

Support for this work is provided in part by the Danish Research Council (Grant no. 274-06-0465), and the Myhrwold, and Otto Mønsted Foundations. The authors wish to acknowledge discussion with Petros Koumoutsakos and Dimos Poulikakos and computational support from the Danish Center for Scientific Computing (DCSC).

${ }^{1}$ H. Somada, K. Hirahara, S. Akita, and Y. Nakayama, Nano Lett. 9, 62 (2009).

${ }^{2}$ A. Barreiro, R. Rurali, E. R. Hernández, J. Moser, T. Pichler, L. Forró, and A. Bachtold, Science 320, 775 (2008).

${ }^{3}$ P. A. E. Schoen, J. H. Walther, S. Arcidiacono, D. Poulikakos, and P. Koumoutsakos, Nano Lett. 6, 1910 (2006).

${ }^{4}$ P. A. E. Schoen, J. H. Walther, D. Poulikakos, and P. Koumoutsakos, Appl. Phys. Lett. 90, 253116 (2007).

${ }^{5}$ P. A. E. Schoen, J. H. Walther, D. Poulikakos, and P. Koumoutsakos, Appl. Phys. Lett. 91, 079901 (2007).

${ }^{6}$ H. A. Zambrano, J. H. Walther, P. Koumoutsakos, and I. F. Sbalzarini, Nano Lett. 9, 66 (2009).

${ }^{7}$ Y. Ueno, H. Somada, K. Hirahara, Y. Nakayama, and S. Akita, Jpn. J. Appl. Phys. 48, 06FG03 (2009).

${ }^{8}$ B. W. Smith, M. Monthioux, and D. E. Luzzi, Chem. Phys. Lett. 315, 31 (1999).

${ }^{9}$ R. Gasparac, P. Kohli, M. O. Mota, L. Trofin, and C. R. Martin, Nano Lett. 4, 513 (2004).

${ }^{10}$ B. C. Regan, S. Aloni, R. O. Ritchie, U. Dahmen, and A. Zettl, Nature (London) 428, 924 (2004).

${ }^{11}$ K. Svensson, H. Olin, and E. Olsson, Phys. Rev. Lett. 93, 145901 (2004).

${ }^{12}$ A. S. Fedorov and A. F. Sadreev, Eur. Phys. J. B 69, 363 (2009).

${ }^{13}$ J. Shiomi and S. Maruyama, Nanotechnology 20, 055708 (2009).

${ }^{14}$ G. E. Begtrup, W. Gannet, T. D. Yuzvinsky, V. H. Crespi, and A. Zettl, Nano Lett. 9, 1835 (2009).

${ }^{15}$ J. M. Howe, T. Yokota, M. Murayama, and W. A. Jesser, J. Electron Microsc. 53, 107 (2004).

${ }^{16}$ T. Yokota, M. Murayama, and J. Howe, Phys. Rev. Lett. 91, 265504 (2003).

${ }^{17}$ J. S. Wang, J. Wang, and J. T. Lu, Eur. Phys. J. B 62, 381 (2008).

${ }^{18}$ J. Biskupek, U. Kaiser, and F. Falk, J. Electron Microsc. 57, 83 (2008).

${ }^{19}$ A. V. Krasheninnikov, J. Comput. Theor. Nanosci. 5, 1828 (2008).

${ }^{20}$ A. V. Krasheninnikov and F. Banhart, Nature Mater. 6, 723 (2007)

${ }^{21}$ J. H. Walther, R. Jaffe, T. Halicioglu, and P. Koumoutsakos, J. Phys. Chem. B 105, 9980 (2001)

${ }^{22}$ T. A. Hilder and J. M. Hill, Drug Delivery 5, 300 (2009).

${ }^{23}$ T. A. Hilder and J. M. Hill, Nanotechnology 18, 275704 (2007).

${ }^{24}$ D. Baowan, N. Thamwattana, and J. M. Hill, Phys. Rev. B 76, 155411 (2007).

${ }^{25}$ M. Yoon, S. Berber, and D. Tomanek, Phys. Rev. B 71, 155406 (2005).

${ }^{26}$ Q. Chen, Q. Wang, Y. C. Liu, T. Wu, Y. Kang, J. D. Moore, and K. E. Gubbins, J. Chem. Phys. 131, 015101 (2009).

${ }^{27}$ H. Gao, Y. Kong, and D. Cui, Nano Lett. 3, 471 (2003).

${ }^{28}$ D. Mattia and Y. Gogotsi, Microfluid. Nanofluid. 5, 289 (2008). 